\title{
Zeolite-Templated Carbon as the Cathode for a High Energy Density Dual-Ion Battery
}

\section{Authors: Romain J. - C. Dubey, Jasmin Nussli, Laura Piveteau, Kostiantyn V. Kravchyk, Marta D. Rossell, Marco Campanini, Rolf Erni, Maksym V. Kovalenko, and Nicholas P. Stadie}

This document is the unedited author's version of a Submitted Work that was subsequently accepted for publication in ACS Applied Materials \& Interfaces, copyright @ American Chemical Society after peer review. To access the final edited and published work, see DOI:10.1021/ acsami.9b03886

Dubey, Romain J-C, Jasmin Nussli, Laura Piveteau, Kostiantyn V. Kravchyk, Marta D. Rossell, Marco Campanini, Rolf Erni, Maksym V. Kovalenko, and Nicholas P. Stadie. "Zeolite-Templated Carbon as the Cathode for a High Energy Density Dual-Ion Battery.." ACS Applied Materials \& Interfaces 11, no. 19 (April 2019): 17686-11696. DOI:10.1021/acsami.9b03886. 


\title{
Zeolite-Templated Carbon as the Cathode for a High Energy Density Dual-Ion Battery
}

\author{
Romain J.-C. Dubey ${ }^{\dagger \ddagger}$, Jasmin Nüssli†‡, Laura Piveteau ${ }^{\dagger}$, Kostiantyn V. Kravchyk ${ }^{\dagger \ddagger}$, Marta D. Ros- \\ sell", Marco Campanini", Rolf Erni", Maksym V. Kovalenko ${ }^{\ddagger *}$ and Nicholas P. Stadie ${ }^{\# *}$
}

†Laboratory of Inorganic Chemistry, Department of Chemistry and Applied Biosciences, ETH Zürich, CH-8093 Zürich, Switzerland

‡Laboratory for Thin Films and Photovoltaics, Empa, Swiss Federal Laboratories for Materials Science \& Technology, CH-8600 Dübendorf, Switzerland

"Electron Microscopy Center, Empa, Swiss Federal Laboratories for Materials Science \& Technology, CH-8600 Dübendorf, Switzerland

\#Department of Chemistry \& Biochemistry, Montana State University, Bozeman, Montana, 59717, United States

\begin{abstract}
Dual-ion batteries (DIBs) are electrochemical energy storage devices that operate by the simultaneous participation of two different ion species at the anode and the cathode and rely on the use of an electrolyte that can withstand the high operation potential of the cathode. Under such conditions at the cathode, issues associated with irreversible capacity loss and the formation of solid-electrolyte interphase (SEI) at the surface of highly porous electrode materials are far less significant than at lower potentials, permitting the exploration of high surface area, permanently porous framework materials as effective charge storage media. This concept is investigated herein by employing zeolite-templated carbon (ZTC) as the cathode in a dual-ion battery based on a potassium bis(fluorosulfonyl)imide (KFSI) electrolyte. Anion (FSI) insertion within the pore network during electrochemical cycling is confirmed by NMR spectroscopy, and the maximum charge capacity is found to be proportional to surface area and micropore volume by comparison to other microporous carbon materials. Fullcells based on ZTC as the cathode exhibit both high specific energy (up to $176 \mathrm{Wh} \mathrm{kg}^{-1}, 79.8 \mathrm{Wh} \mathrm{L}^{-1}$ ) and high specific power (up to $3945 \mathrm{~W} \mathrm{~kg}^{-1}, 1095 \mathrm{~W} \mathrm{~L}^{-1}$ ), stable cycling performance over hundreds of cycles, and reversibility within the potential range of 2.65-4.7 V vs. $\mathrm{K} / \mathrm{K}^{+}$.
\end{abstract}

KEYWORDS: potassium, bis(fluorosulfonyl)imide, capacitive, microporous, electrode, electrochemical energy storage

\section{INTRODUCTION}

Dual-ion batteries ${ }^{1-5}$ (DIBs) are an emerging class of electrochemical energy storage devices that are distinguished from common "shuttle-type" or "rocking chair" batteries such as lithium-ion batteries (LIBs) that rely on the participation of only a single type of ion $\left(e . g ., \mathrm{Li}^{+}\right)$at both electrodes. In a DIB cell, two types of ions (a cation and anion pair) co-mingle in the bulk electrolyte in the discharged state. Upon charging, the large (typically polyatomic) anions are oxidatively inserted into the cathode material, a process that occurs at high potential relative to the reversible electroplating, alloying, or insertion reaction of the cation at the anode. The mainstay of research into compounds that can readily host anionic species has remained focused on nonporous solids such as graphite ${ }^{6-}$ ${ }^{15}$, nanostructured graphitic materials ${ }^{16-20}$, amorphous carbon materials (e.g., hard carbon ${ }^{21}$, mesocarbon microbeads ${ }^{22}$, and microbead films ${ }^{23}$ ), hydrocarbons (e.g., polycyclic aromatic hydrocarbons ${ }^{24,25}$ and aromatic diamines ${ }^{26}$ ), conductive polymers $^{27-29}$, and some metals (e.g., metal fluorides ${ }^{30}$ ). A 3D porous carbon has been investigated as a high stability current collector for graphite-based DIBs. ${ }^{31}$ On the contrary, little attention has been paid to the use of high surface area microporous $^{32}$ materials as exclusively capacitive-type cathode materials in DIBs (although redox-active metal-organic frameworks (MOFs) have indeed begun to be explored ${ }^{33-35}$ ).

In this work, we draw attention to two key features of DIBs that lend great potential promise to conductive microporous materials carrying a large accessible inner surface to serve as a high-capacity and high-rate capability, purely capacitive cathode material: (i) the high working potential of the cathodic reaction occurring at the porous material surface and (ii) the large size of the anions typically employed. The high potential of anion insertion/de-insertion significantly mitigates the irreversible loss of energy density associated with excessive solid-electrolyte interphase (SEI) formation during the first several cycles, a well-known problem associated with the low potential adsorption of cations at the surface of porous anode materials in shuttle-type batteries. ${ }^{36-39}$ Furthermore, the oxidative insertion of anions is, in general, a notoriously challenging reaction to perform reversibly and/or at high rates within condensed solid-state media (as compared to the reductive insertion of smaller cations). This observation is often attributed mainly to the larger size of the anions employed, ${ }^{40}$ although such size effects have been shown to be complexly related to other electrolyte effects, such as ion-pair formation and self-aggregation. ${ }^{41}$ These observations together strongly incentivize the exploration of highly porous 
materials that are both conductive and that can easily accommodate large, polyatomic anions by adsorption on their inner surfaces as both high energy- and power-density electrodes in DIBs.

While some MOFs are redox-active and/or electrically conductive, most are neither. ${ }^{42}$ Carbon-based porous materials such as activated carbon, on the other hand, are known to exhibit very large surface areas and micropore volumes, akin to MOFs, and to exhibit modest electrical conductivity, while also remaining inexpensive to produce and only consisting of highly Earth-abundant constituent elements. Indeed, activated carbons serve as the standard electrode materials in electrochemical capacitors (i.e., supercapacitors) for these reasons, and owing to their ability to be both oxidized and reduced. Capacitive charge storage increases as a function of surface area, 43,44 and the highest surface area carbon materials exhibit benchmark electrochemical capacitance in both aqueous and organic electrolytes. ${ }^{36}$

Zeolite-templated carbon (ZTC) represents an extreme limit of ultra-high surface area, carbon-based framework materials. ZTC is synthesized within a crystalline microporous silicate (zeolite) template, exhibiting an ordered network of pores with an extremely narrow pore size distribution made up exclusively of micropores. ${ }^{39}$ The most well-understood ZTC structure is the variant derived from faujasite (FAU-ZTC) which features $\sim 1.2 \mathrm{~nm}$ pores separated by curved graphenelike struts composed of disordered and irregular polycyclic carbon fragments. ${ }^{45}$ While the atomic-level structure of FAUZTC is disordered, the pore-to-pore regularity (imparted by the zeolite template during synthesis) is very high, and the volumetric density of homogeneous micropores is higher than that of any other predominantly $\mathrm{sp}^{2}$-hybridized carbonbased material. Importantly, the three-dimensionally connected structure of ZTC is sufficiently conductive ${ }^{46}$ to permit its use as a bare (capacitive- or pseudocapacitive-type) electrode material in electrochemical capacitors ${ }^{4-54}$ (supercapacitors) and batteries ${ }^{55}$, even at very high current rates ${ }^{48}$ and low temperatures ${ }^{56}$. These traits make ZTC an ideal material for hosting large, polyatomic anionic species via a capacitive storage mechanism on its inner surface.

In this work, potassium bis(fluorosulfonyl)imide (KFSI) DIB cells based on ZTC along with several other bare porous carbon materials were prepared and characterized as a proof-ofprinciple, and to determine the dependence of the charge storage capacity (i.e., anion uptake) on the surface area and micropore volume. Bis(fluorosulfonyl)imide (FSI-) was chosen as an optimal anion due to its demonstrated successful use in DIBs, ${ }^{41,}{ }^{57}$ high oxidative stability, ${ }^{58}$ and solubility even in high concentrations in mixtures of ethylene carbonate (EC) and dimethyl carbonate (DMC), permitting high energy and power densities in full-cell DIB prototypes. Potassium was chosen as a suitable counter ion owing to its high natural abundance and good electroplating/stripping characteristics under the conditions necessary for FSI $^{-}$insertion into ZTC (imparting a similarly high cell voltage to lithium but being $>100 \times$ more abundant in Earth's upper crust). The full-cell is thus comprised only of highly abundant elements (C, K, N, S, $\mathrm{O}$, and $\mathrm{F}$ ) and a schematic of the working principle of this KFSI DIB concept is shown in Figure 1, depicting FSI- insertion into ZTC during charging.
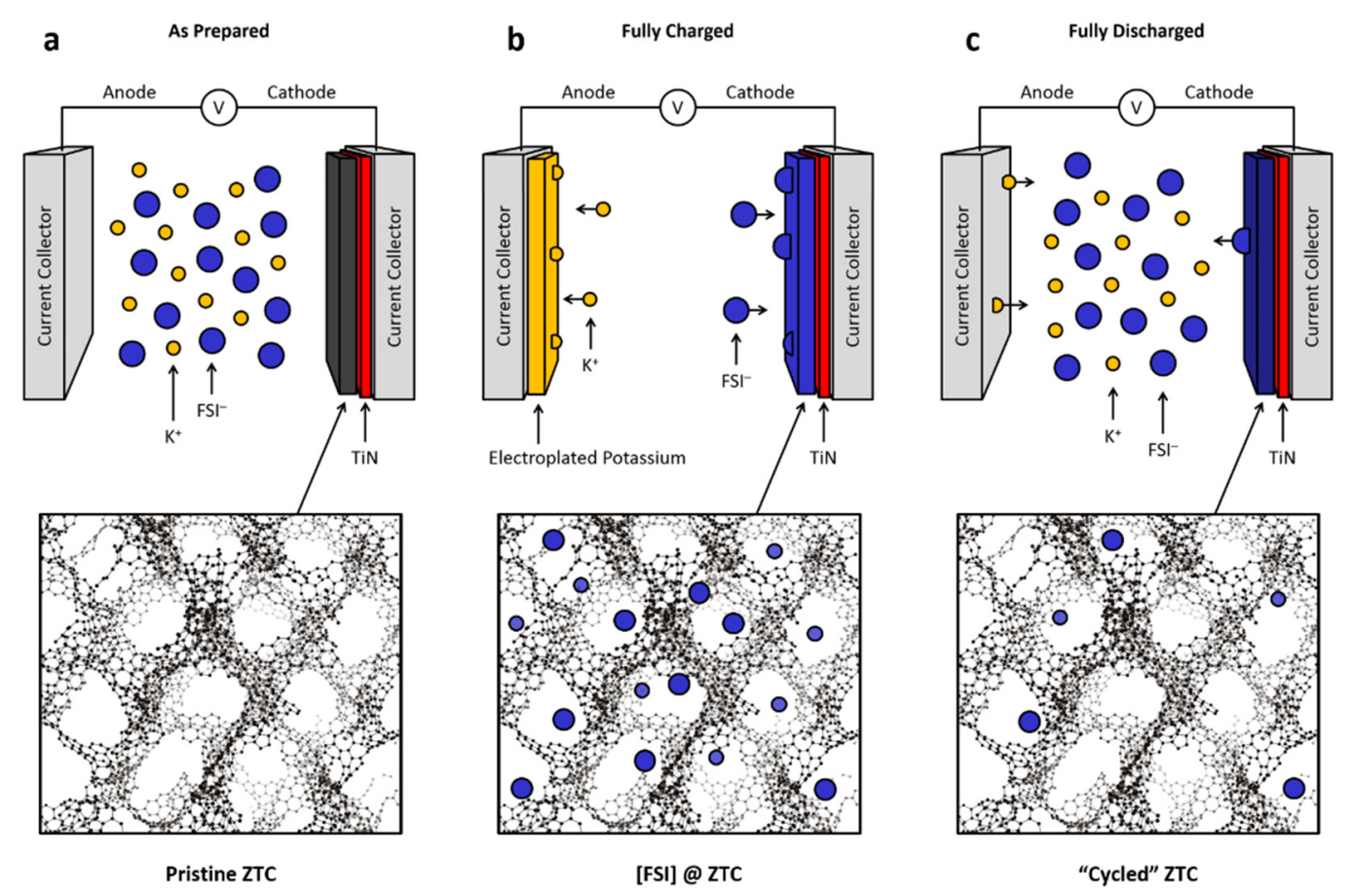

Figure 1. Schematic Depiction of the Working Principle of a KFSI DIB Employing ZTC as the Active Cathode Material. (a) In the asprepared cell, pristine (unoccupied) ZTC is dispersed onto a TiN-coated stainless steel current collector and the electrolyte solution (KFSI in EC/DMC) is allowed to wet all components freely. (b) Upon charging of the cell, $\mathrm{K}^{+}$cations combine with electrons at the anode and electroplating of metallic potassium occurs. Concomitantly, FSI- anions insert into the oxidized ZTC framework and [FSI]@ZTC is formed in the fully charged state. (c) Upon discharge, $\mathrm{K}^{+}$cations are stripped from the anode back into solution and electrons travel to the cathode, recombining with the ZTC framework; most of the FSI- anions leave the ZTC and redissolve into the electrolyte, while some remain irreversibly adsorbed within the ZTC. 
KFSI DIBs based on ZTC as the cathode were found herein to exhibit a high reversible specific gravimetric capacity (up to $141 \mathrm{mAh} \mathrm{g}^{-1}$ ) even at high current rates, over hundreds of cycles. Importantly, the average voltage was found to be 3.0-3.5 $\mathrm{V}$ vs. $\mathrm{K} / \mathrm{K}^{+}$(depending on the current rate), leading to very high specific energy densities (up to $485 \mathrm{Wh} \mathrm{kg}^{-1}$ ) and power densities (up to $5785 \mathrm{~W} \mathrm{~kg}^{-1}$ ) for the ZTC itself as a bare cathode. In full-cells, DIBs employing ZTC as the cathode are estimated to achieve values of $176 \mathrm{Wh} \mathrm{kg}^{-1}$ and $3945 \mathrm{~W} \mathrm{~kg}^{-1}$ under the conditions investigated herein, which compare favorably to state-of-the-art LIBs. As in previous work exploring both microporous carbons ${ }^{55}$ and other carbon-based materials ${ }^{16,29 \text {, }}$ 59-61 as electrodes in aluminum batteries (ABs) , the irreversible capacity loss associated with formation of SEI in the first several charge/discharge cycles was greatly mitigated. Unlike past work, on the other hand, significantly higher energy and power densities could be achieved in ZTC-based KFSI DIBs, owing to a much higher operating voltage and a higher concentration of electrolyte in the cell. This work lays a foundation for further pursuits of electrode/electrolyte combinations that provide stable, high-voltage operation by anion insertion within the microporous networks of high surface area carbonaceous materials such as ZTC.

\section{RESULTS AND DISCUSSION}

Synthesis of ZTC. The faujasite variant of zeolite-templated carbon (FAU-ZTC) was synthesized by the well-established two-step method, comprising the liquid-phase impregnation of a Y-type zeolite with furfuryl alcohol and gas-phase impregnation of propylene. The chemical vapor deposition (CVD) (high surface area and pore-to-pore regularity and minimal graphitic content) based on previous results. ${ }^{55}$ Heat treatment at $900{ }^{\circ} \mathrm{C}$ to anneal the underlying carbon framework was followed by cooling and dissolution in aqueous HF to free the final ZTC product. Detailed synthetic methods are given in the Supporting Information.

Materials Characterization. The high template-fidelity nature of the FAU-ZTC structure (and hence high surface area and pore regularity) was evidenced by X-ray powder diffraction (XRD), nitrogen adsorption, and electron microscopy (see Figure 2). The intense XRD reflection centered at $2 \theta=$ $6.5^{\circ}(\mathrm{d}$-spacing $=1.36 \mathrm{~nm})$ indicates the high pore-to-pore regularity of FAU-ZTC inherited from the zeolite NaY template, while the absence of higher order peaks is indicative of its generally amorphous local atomic structure (Figure 2a). ${ }^{62}$ Pore-to-pore regularity was also clearly observed in transmission electron microscopy (TEM) investigations, with periodic contrast patterns parallel to the ZTC particle edges exhibiting an average spacing of $\sim 1.4 \mathrm{~nm}$ (Figures 2c-2d, Figures S2-S3). Scanning electron microscopy (SEM) studies at lower magnification confirm that the size and shape of the ZTC particles are identical to the microcrystalline zeolite NaY template (see Figure S1).

Nitrogen adsorption/desorption isotherms at $77 \mathrm{~K}$ confirm the exclusively microporous structure and high surface area of ZTC (Figure $\mathbf{2 b}$ ). The isotherms exhibit a pronounced knee at $\mathrm{P} / \mathrm{P}_{0}=\sim 0.12$, a relatively flat adsorption uptake plateau between 780-920 mLstP $\mathrm{g}^{-1}$, and no apparent adsorption/ desorption hysteresis, all indicative of exclusively microporous structure.
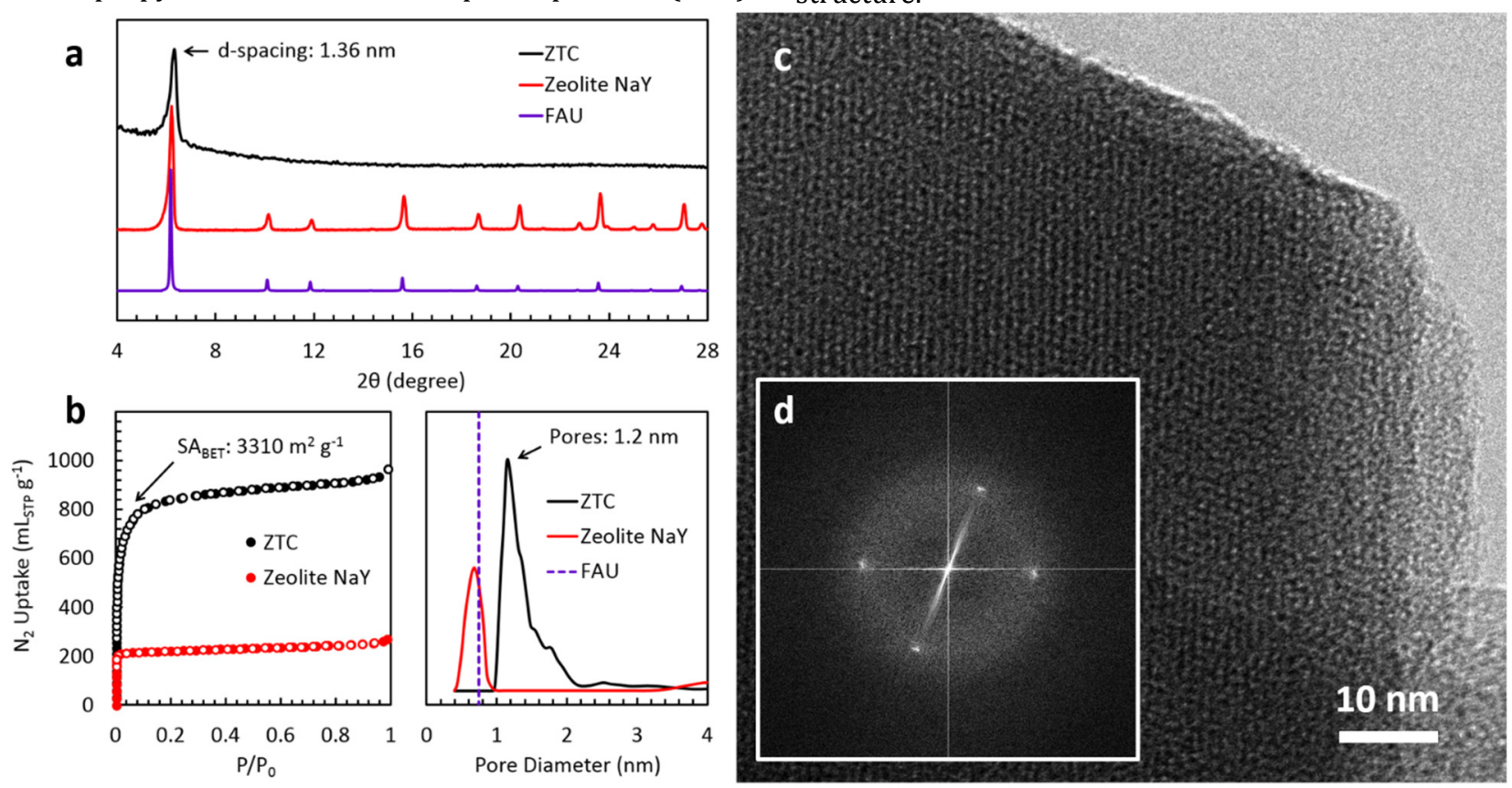

conditions employed for propylene insertion and pyrolysis within the zeolite were optimized for high template fidelity

Figure 2. Structure of Zeolite-Templated Carbon (ZTC). (a) X-ray diffraction (XRD) pattern of ZTC (black) compared to that of the native zeolite template (red) and the calculated FAU zeolite crystal structure (purple). (b) Equilibrium $\mathrm{N}_{2}$ adsorption/desorption isotherms at $77 \mathrm{~K}$ of ZTC (black) compared to its template (red) and corresponding non-local density functional theory (NLDFT) pore-size distributions compared to the theoretical diameter of the theoretical FAU 12-ring pore openings (purple dashed). (c) Zeroloss filtered transmission electron micrograph of a ZTC particle revealing the long-range pore ordering. The pores are aligned perpendicular to the image plane and oriented perpendicular to the particle edge as confirmed by (d) the corresponding Fourier transform image. 
The adsorption branch was fitted to the Brunauer-EmmettTeller (BET) isotherm equation between $\mathrm{P} / \mathrm{P}_{0}=0.02-0.8$ according to the standard consistency criteria for microporous materials ${ }^{63}$, yielding a monolayer capacity of $760 \mathrm{mLsTP}^{-1}$ and a BET surface area of $3310 \mathrm{~m}^{2} \mathrm{~g}^{-1}$ (see Figure S4). It should be noted that this value is significantly higher than that of a pristine double-sided sheet of graphene $\left(2650 \mathrm{~m}^{2} \mathrm{~g}^{-1}\right)$ owing to significant edge-character of the ZTC structure. The micropore volume of ZTC was found to be $1.41 \mathrm{~mL} \mathrm{~g}^{-1}$, as determined by Dubinin-Radushkevich (DR) analysis (see Figure S5). Non-local density functional theory (NLDFT) analysis of the adsorption branch reveals a narrow pore-size distribution centered at a diameter of $1.19 \mathrm{~nm}$ (Figure 2c). The slightly longer overall pore-to-pore regularity of $\sim 1.4 \mathrm{~nm}$ measured by XRD and TEM indicates that the pore walls in ZTC are atomically thin $(<0.3 \mathrm{~nm})$ and that all carbon surfaces are exposed on both sides. Together, these results are consistent with the open, double-sided graphene-fragment based molecular model of archetypical FAU-ZTC. ${ }^{45}$

Electrochemical Oxidation of ZTC in KFSI Electrolyte. The electrochemical oxidation of ZTC in the presence of KFSI electrolyte was assessed in an analogous way as for recent investigations of FSI- intercalation in graphite. $^{64}$ The relevant electrochemical reactions proceed as follows (where the forward direction occurs during charging):

$$
\begin{array}{lc}
\text { Anode: } & \mathrm{K}^{+}+\mathrm{e}^{-} \leftrightarrow \mathrm{K} \\
\text { Cathode: } & x \mathrm{C}+\mathrm{FSI}^{-} \leftrightarrow[\mathrm{FSI}] \mathrm{C}_{x}+\mathrm{e}^{-}
\end{array}
$$

For graphite, it was found that the upper limit of FSI- incorporation corresponds to a stage 1 intercalation compound with a composition of [FSI]C 12 (i.e., $x=12$ in Equation 2) and the charge/discharge voltage plateau is at $4.7-4.8 \mathrm{~V}$ vs. $\mathrm{K} / \mathrm{K}^{+} .64$

The charging process ends when all of the $\mathrm{K}^{+}$cations or FSI anions are depleted in the electrolyte, or when the ZTC cathode reaches its maximum charge storage capacity. In this work, anticipating a similarly high voltage of operation as in graphite, a range of electrolyte compositions in several organic solvents and mixtures thereof were investigated with the goal of determining a solution with an appropriate voltage stability and the highest possible concentration of KFSI. It should be noted that the KFSI solution serves as both an electrolyte (i.e., ion conduction medium) and as the source of electroactive species; the concentration of the electrolyte is a limiting factor in the energy density of the final cell (see Supporting Information for details) and must be maximized. Preliminary experimental results on the electrochemical performance of ZTC-based KFSI DIBs with different electrolyte concentrations also revealed that higher concentration was correlated with higher charge storage capacity (Figure S7). Therefore, there is a two-fold contribution of the electrolyte concentration to energy and power density due to the higher ZTC cathodic capacity contribution. Based on these considerations, all electrochemical experiments carried out in this work were performed using a high concentration electrolyte: 4.8 M KFSI in EC/DMC (1:1 by weight). It should be noted that the large volume expansion of the electrolyte solution upon dissolution of KFSI leads to a significantly lower actual concentration than initially mixed (e.g., the true concentration of a nominally $10 \mathrm{M}$ solution is only $4.84 \mathrm{M}$ when measured by final volume). Higher concentrations of the KFSI salt in the EC/DMC mixture are possible, but were found to result in viscosities that serve to significantly reduce ionic conductivity as well as long wetting times, and were therefore abandoned.

The type of charge storage mechanism ${ }^{65}$ as well as the stability window ${ }^{66}$ of electrochemical oxidation of ZTC were assessed by cyclic voltammetry (CV) measurements carried out in $4.8 \mathrm{M} \mathrm{KFSI}$ in EC/DMC (1:1 by weight). Early experiments suggested that the electrochemical oxidation behavior of pristine ZTC in the presence of KFSI was markedly different during the first several (typically six) electrochemical cycles, indicating some irreversibility in the electrochemical reactions undergone during the early stages of oxidation of the ZTC framework, and likely SEI formation at the surface. The specific nature of these first six cycles (scan rate, voltage range, etc.) was found to play a significant role in the eventual reversible electrochemical characteristics of the ZTC. Hence, a specific pretreatment regimen needed to be established that optimally prepared the ZTC for further electrochemical characterization and eventually for optimal electrode preparation (see Supporting Information for details). The optimal pretreatment regimen was determined to consist of six galvanostatic cycles between $2.65-4.7 \mathrm{~V}$ vs. $\mathrm{K} / \mathrm{K}^{+}$at $120 \mathrm{~mA} \mathrm{~g}^{-1}$ after which all other electrochemical characterization was carried out.

Successive CV measurements within incrementally widening voltage windows were then used to determine the limits of reversible oxidation (FSI- insertion) and reduction $\left(\mathrm{K}^{+}\right.$insertion) of ZTC (with further details provided in the Supporting Information). An overall "stability window" of $\sim 1.0-4.8 \mathrm{~V}$ vs. $\mathrm{K} / \mathrm{K}^{+}$was determined for ZTC (Figure S8); this is consistent with previous reports of the electrochemical stability of ZTC in other electrolytes (e.g., 1.2 to $4.7 \mathrm{~V} \mathrm{vs.} \mathrm{Li}^{-\mathrm{Li}^{+}}$in $1 \mathrm{M}$ $\mathrm{LiPF}_{6}$ in EC/DEC). ${ }^{39}$ However, it should be noted that there is a difference between the "stability window" and the optimal window of operation in a full-cell KFSI DIB. Galvanostatic discharge and differential capacity measurements of ZTC within the full voltage range of $1.0-4.7 \mathrm{~V}$ vs. $\mathrm{K} / \mathrm{K}^{+}$show a sharp decline in $\mathrm{dQ} / \mathrm{dV}$ intensity below $2.65 \mathrm{~V}$ indicating the start of (undesirable) $\mathrm{K}^{+}$ion insertion within ZTC (Figure S9). Therefore, the optimal window of operation of a KFSI DIB cell employing ZTC as the active cathode material for the exclusive insertion/removal of FSI- ions was determined to be 2.65-4.7 $\mathrm{V}$ vs. $\mathrm{K} / \mathrm{K}^{+}$. Within this range, "cycled" ZTC shows highly reversible behavior even at slow scan rates down to $0.1 \mathrm{mV} \mathrm{s}^{-1}$ and a strictly capacitive mechanism of charge storage (Figure S10).

ZTC as the Cathode in a KFSI DIB Cell. Electrochemical cells comprising pristine ZTC as the cathode (and a thin layer of potassium on stainless steel as the anode) in 4.8 M KFSI in EC/DMC (1:1 by weight) were prepared and galvanostatically cycled between 2.65-4.7 V vs. K/K+ (see Figure 3). At the lowest current rate investigated $\left(120 \mathrm{~mA} \mathrm{~g}^{-1}\right)$, the specific discharge capacity of ZTC was measured to be $139.5 \mathrm{mAh} \mathrm{g}^{-1}$ during the $6^{\text {th }}$ cycle, representing a $\sim 40 \%$ increase over graphite $^{64}$, at an average voltage of $3.49 \mathrm{~V}$ vs. $\mathrm{K} / \mathrm{K}^{+}$. For comparison, identical KFSI DIB cells comprising several other porous carbon cathode materials were also tested within the same voltage window (Figure 3a). The reversible specific discharge capacity of each cathode material was found to be linearly dependent on both the BET specific surface area and the DR specific micropore volume of the bare porous carbon (see Figure S6). With regard to surface area, this corresponds to a packing 
density of $0.947 \mathrm{FSI}^{-}$anions per $\mathrm{nm}^{2}$ of nitrogen-accessible surface at $120 \mathrm{~mA} \mathrm{~g}^{-1}$. Having the highest specific surface area and largest micropore volume, ZTC was selected, as expected, for all further detailed electrochemical analyses.

Upon extended electrochemical cycling, it was observed that reversible operation (coulombic efficiency of $>99 \%$ ) of ZTC as the cathode in a KFSI DIB was achieved after the first six cycles (see Figure S11) and could be maintained for several hundred cycles (Figure 3b). At $120 \mathrm{~mA} \mathrm{~g}^{-1}$, the stable discharge capacity was increased slightly up to $141 \mathrm{mAh} \mathrm{g}^{-1}$ after $>300$ cycles. The dependence of the specific discharge capacity and average discharge voltage on current density were determined by variable current cycling as shown in Figures 3c3d. At $480 \mathrm{~mA} \mathrm{~g}^{-1}$, the stable discharge capacity was reduced to $97 \mathrm{mAh} \mathrm{g}^{-1}, \sim 70 \%$ of the initial stable discharge capacity at $120 \mathrm{~mA} \mathrm{~g}^{-1}$. The charge/discharge voltage profiles at all current rates were found to be continuously sloped and do not exhibit any insertion/de-insertion plateaux, which is consistent with the capacitive mechanism of charge storage as determined by cyclic voltammetry.

At a current rate of $120 \mathrm{~mA} \mathrm{~g}^{-1}$, the cathode-specific energy and power density of ZTC are calculated to be $485 \mathrm{Wh} \mathrm{kg}^{-1}$ and $418 \mathrm{~W} \mathrm{~kg}^{-1}$, respectively, as detailed in the Supporting Information. The energy density was found to increase linearly with specific surface area while power density was approximately constant across all of the porous carbon cathode materials investigated (see Figure S16). Some scatter in the data is observed, indicating the likely relevance of other materials properties such as pore size, chemical composition, and edge contribution of the surface, as has been investigated in polyaromatic hydrocarbon molecular solids ${ }^{25}$. On the other hand, the energy density of ZTC was found to decrease linearly with increasing current rate (modestly, as expected) while power density increased linearly with current rate (between 120$1920 \mathrm{~mA} \mathrm{~g}^{-1}$ ).
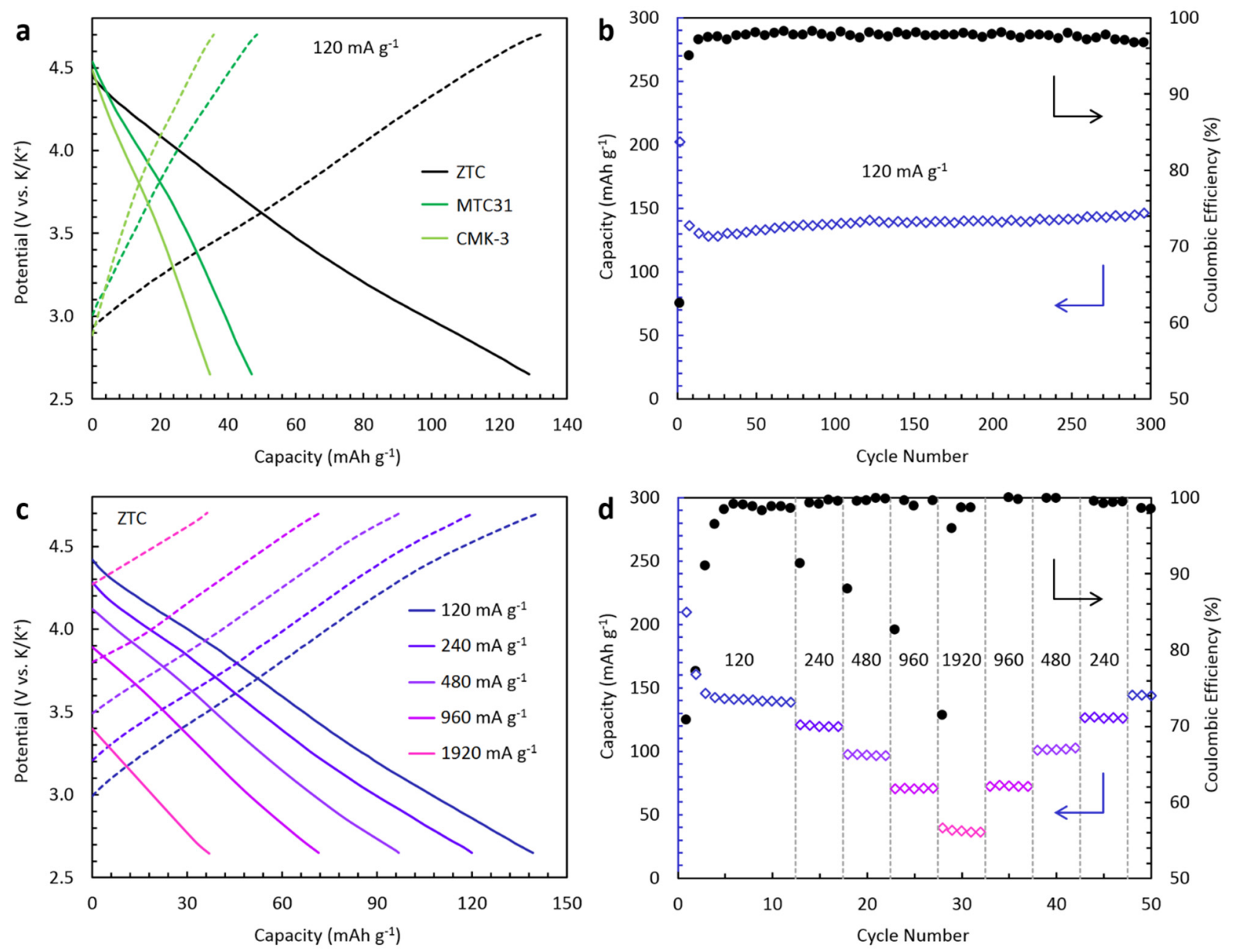

Figure 3. Electrochemical Characterization of Microporous Carbon Materials as the Cathode in Dual-Ion KFSI Batteries. (a) Galvanostatic charge/discharge voltage profiles of ZTC (black), and two lower surface area porous carbon materials (green and light green) during the $20^{\text {th }}$ cycle, at a current rate of $120 \mathrm{~mA} \mathrm{~g}^{-1}$. The capacity (at $2.65 \mathrm{~V}$ during discharge) is proportional to BET specific surface area (BET SA), related by a factor of $37.8 \mathrm{mAh}$ per $1000 \mathrm{~m}^{2}$ of nitrogen-accessible surface area. (b) Discharge capacity (open diamonds) and coulombic efficiency (filled circles) over 300 cycles for ZTC KFSI DIBs cycled between 2.65-4.7 V at 120 mA g-1. (c) Galvanostatic charge/discharge voltage profiles of ZTC during the $12^{\text {th }}, 17^{\text {th }}, 22^{\text {nd }}, 27^{\text {th }}$, and $32^{\text {nd }}$ cycles, at various current rates between 120-1920 mA g-1 as specified by color. (d) Discharge capacity retention (open diamonds) and coulombic efficiency (filled circles) over the same 50 cycles at the current rates indicated. 
This is an indication that the mechanism of charge storage is not limited by diffusion within the porous framework of ZTC.

Evidence for Insertion of FSI- into ZTC. A combination of ${ }^{19} \mathrm{~F}$ and ${ }^{13} \mathrm{C}$ solid-state NMR experiments were carried out to verify the successful insertion of $\mathrm{FSI}^{-}$anions within the pore structure of ZTC during charge/discharge cycling of the above described cells. A series of samples consisting of pristine (unoccupied) and solution-impregnated [FSI]@ZTC were compared to ex situ recovered samples of electrochemically-cycled ZTC (in either the fully charged or fully discharged state). To assist in distinguishing the contributions from adsorbed FSI- and free FSI- dissolved in solution (potentially a contaminant on the outer surfaces of the ex situ recovered samples), a washing regimen was established that consists of carefully rinsing the ZTC particles with EC/DMC (1:1 by weight) after which the samples could be compared with and without washing (details given in Supporting Information).

Static and magic angle spinning (MAS) ${ }^{19} \mathrm{~F}$ solid-state NMR experiments showed several common features in all spectra, including two strong signals at $-148 \mathrm{ppm}$ and $-84 \mathrm{ppm}$ that can be attributed to instrument-related background, as shown in Figure 4 and Figure S13. In the spectra for all samples except the pristine ZTC, a distinct signal at $52 \mathrm{ppm}$ is observed, corresponding to the presence of freely tumbling $\mathrm{FSI}^{-}$ (as confirmed by solution-state NMR of the neat liquid electrolyte solution).

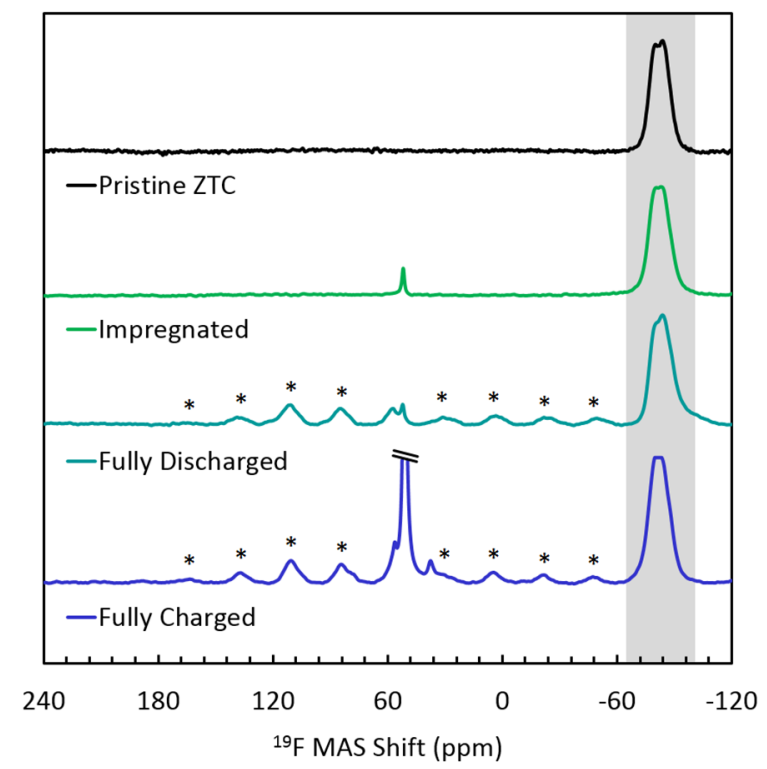

Figure 4. ${ }^{19} \mathrm{~F}$ MAS NMR (10 kHz) spectra of pristine, impregnated, and electrochemically cycled ZTC. The gray shaded region indicates signal originating from instrument background. The starred peaks surrounding the signal at $57 \mathrm{ppm}$ are spinning sidebands resulting from a large chemical shift anisotropy (CSA), demonstrating immobilized FSI- anions. This species is present in the spectra of charged and discharged ZTC, which indicates its origin as irreversibly adsorbed FSI- anions inserted during the first six cycles of cell operation. The very intense and broad ( $405 \mathrm{~Hz}$ ) signal at $52 \mathrm{ppm}$ in charged ZTC, corresponding to semi-mobile adsorbed $\mathrm{FSI}^{-}$anions, is evidence of the reversibly adsorbed FSI- $^{-}$species inserted during each cycle.
This indicates that despite the washing treatment, some solubilized FSI- does remain in/on all samples, although far less significantly in the case of the washed samples (Figure S13). The linewidths of this signal in the second set of ${ }^{19} \mathrm{~F}$ solid-state NMR experiments under MAS conditions $\left(90^{\circ}\right.$-one-pulse sequence at $10 \mathrm{kHz}$ ) can be directly compared to determine the relative mobility of the solubilized FSI- species (see Figure 4). The narrow signal at $52 \mathrm{ppm}$ (exhibiting a linewidth of $74 \mathrm{~Hz}$ ) for the solution-impregnated (and washed) ZTC is associated with dissolved $\mathrm{FSI}^{-}$as in the neat liquid electrolyte solution (likely on the outer surfaces of the ZTC particles, as consistent with the results from static NMR experiments). For fully charged ZTC, an intense signal at $52 \mathrm{ppm}$ is accompanied by another centered at $57 \mathrm{ppm}$ that also exhibits several spinning sidebands, both corresponding to the presence of FSIThe primary signal at $52 \mathrm{ppm}$, exhibiting a linewidth of 405 $\mathrm{Hz}$, is significantly broader than that for solubilized $\mathrm{FSI}^{-}$in neat solution ( $5 \mathrm{~Hz}$ ), indicating that the majority FSI- species in charged ZTC are less mobile than in the solution state. This serves as direct evidence of adsorption of $\mathrm{FSI}^{-}$within the pore network of ZTC during electrochemical charging. The secondary signal at $57 \mathrm{ppm}$, accompanied by spinning sidebands, must arise from a distinct FSI- $^{-}$species that exhibits significant chemical shift anisotropy (CSA). This indicates the presence of a second, fully immobilized FSI- species, attributable to the irreversibly inserted FSI- $^{-}$detected during the first several electrochemical cycles, as previously mentioned. For fully discharged ZTC, the signal at $52 \mathrm{ppm}$ was found to be greatly reduced in intensity and once again relatively narrow $(74 \mathrm{~Hz})$, similarly to the impregnated (and washed) ZTC containing only highly mobile FSI $^{-}$anions in solution on the outer surfaces of the ZTC particles. The discharged sample also shows the signal at $57 \mathrm{ppm}$ with obvious spinning sidebands indicating that the portion of inserted FSI- that is immobilized within the ZTC pore network during charging is indeed not removed during discharge.

The mobility of adsorbed FSI- ions within the pores of fully charged ZTC, while restricted compared to the bulk liquid electrolyte, was still relatively high for an adsorbed phase confined within a narrow, microporous network. This was further investigated by ${ }^{13} \mathrm{C}$ MAS solid-state NMR experiments to determine if EC or DMC were also incorporated along with FSI- during cycling (see Figure S14). Under the conditions employed, no signals originating from the ZTC framework itself were detected, owing to very long relaxation times associated with the weakly conductive and rather amorphous nature of the material. For all samples exposed to the EC/DMC electrolyte mixture and then thoroughly washed (including a drying step at $25^{\circ} \mathrm{C}$ under vacuum), only EC was observed in the ${ }^{13} \mathrm{C}$ NMR spectra (at 66 and $157 \mathrm{ppm}$ ). This implies that, due to its higher boiling point $\left(248{ }^{\circ} \mathrm{C}\right.$ as compared to $90{ }^{\circ} \mathrm{C}$ for DMC), EC did not fully evaporate from all of the external surfaces prior to NMR measurements. It also serves to support the possibility of EC being inserted into the pores of ZTC along with FSI- during charging. If co-inserted during charging, this would permit some (restricted) mobility of the FSI- $^{-}$ ions adsorbed on the inner pore surfaces, and would explain the narrower linewidth than expected for adsorbed FSI- in $^{-}$ fully charged ZTC and the absence of spinning sidebands associated with the signal at $52 \mathrm{ppm}$. Finally, elemental analysis was also carried out on solution-impregnated and electrochemically cycled ZTC, and the results (Table S5 and Figure 
S15) are consistent with the conclusions drawn by NMR analysis (within statistical error).

Pore-Filling Considerations of FSI- Insertion in ZTC. The FSI $^{-}$anion inserted/de-inserted at the ZTC cathode in a KFSI

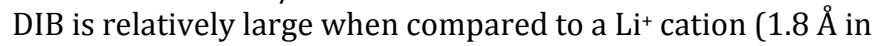
diameter), consisting of two $\left[\mathrm{SO}_{2} \mathrm{~F}\right]$ - ligands bridged by an imide. Its non-spherical shape makes estimation of its effective size more difficult than for other anions such as $\mathrm{AlCl}_{4}^{-}$and $\mathrm{PF}_{6}^{-}$ that have previously been studied in the pores of ZTC. The upper limit of its longer ellipsoidal dimension can be estimated to be as large as $8.6-8.8 \AA$ (based on $2 \times$ that of $\mathrm{SO}_{3} \mathrm{~F}^{67}$ ). Its overall size is estimated to be significantly smaller in other previous work $(5.4 \times 2.6 \AA)$, though a methodology is not given. ${ }^{41}$ Anion size can also be estimated by analysis of the crystal structure of LiFSI, which exhibits a unit cell volume of $779.8(2) \AA^{3}$ (containing 6 formula units); ${ }^{68}$ each FSI- anion occupies $130 \AA^{3}$ (larger than $\mathrm{PF}_{6}-$ at $88.9 \AA^{3}$ but smaller than TFSI ${ }^{-}$at $212 \AA^{3}$ ), corresponding to a cube with a side length of $5.1 \AA$. Based on this volume per FSI- anion, the first cycle discharge capacity of ZTC (203 $\mathrm{mAh} \mathrm{g}^{-1}$ at $\left.120 \mathrm{~mA} \mathrm{~g}^{-1}\right)$ corresponds to $\sim 42 \%$ pore filling of the ZTC framework (based on its measured DR micropore volume of $1.41 \mathrm{~mL} \mathrm{~g}^{-1}$ ). The stable capacity after 200 cycles $\left(141 \mathrm{mAh} \mathrm{g}^{-1}\right.$ at $\left.120 \mathrm{~mA} \mathrm{~g}^{-1}\right)$ corresponds to a reversible filling of $\sim 29 \%$ of the micropore volume of ZTC. Meanwhile, the total irreversible discharge capacity associated with the first six cycles corresponds to the insertion of $7.3 \mathrm{mmol} \mathrm{FSI}^{-}$per gram of ZTC compared to the total of $\sim 5 \mathrm{mmol} \mathrm{g}^{-1}$ inserted and de-inserted per charge/discharge cycle (assuming all of the discharge capacity is a result of FSI- insertion). These calculations indicate that a significant fraction of the total micropore volume of ZTC ( 28\%), even upon maximum insertion of $\mathrm{FSI}^{-}$, remains either unoccupied or occupied with solvent under the conditions investigated herein. While lower current rates would likely lead to higher capacities, this direction was not of interest in this work since it was observed that coulombic efficiency was reduced to $<99 \%$ upon cycling at current rates below $120 \mathrm{~mA} \mathrm{~g}^{-1}$.
Energy and Power Density of Full-Cell KFSI DIBs. A fullcell KFSI DIB consists of a thin metallic potassium film pressed onto stainless steel as the anode, bare ZTC (without any binder or conductive additive) pressed onto TiN-coated stainless steel as the cathode, and 4.8 M KFSI in EC/DMC (1:1 by weight) as both the electrolyte and source of electroactive ions. The majority of the cell's mass lies in the electrolyte solution, which includes both active ion species and the necessary quantity of organic solvent to dissolve them. The specific gravimetric and volumetric full-cell energy and power density can be calculated in several ways but must always account for the crucial mass and volume associated with the electrolyte solution, and also varies depending on the desired charge/discharge current rate (see Supporting Information, especially Tables S6-S9).

A Ragone plot comparing the calculated gravimetric energy and power densities of KFSI DIBs based on ZTC as the cathode in 4.8 M KFSI electrolyte to previously reported DIBs and porous material cathodes is shown in Figure 5. While the bare ZTC cathode material exhibits energy densities of up to 485 Wh kg-1 and power densities of up to $5785 \mathrm{~W} \mathrm{~kg}^{-1}$ (shown as blue symbols), the corresponding values for full-cells are reduced to $176 \mathrm{Wh} \mathrm{kg}^{-1}$ and $3945 \mathrm{~W} \mathrm{~kg}^{-1}$, respectively, for an ideal cell with negligible mass of additional components (the cell case, current collectors, separator, etc.). With simplistic estimates of the mass of these components, the energy and power densities of full cells are further reduced to $164 \mathrm{Wh} \mathrm{kg}$ 1 and $3471 \mathrm{~W} \mathrm{~kg}^{-1}$; however, it should be emphasized that such estimates do not represent accurate end-user values but serve only as a comparison to previous work ${ }^{55}$. In Figure 5, the estimated range of full-cell energy and power densities of ZTC KFSI DIBs (with and without consideration of the additional components) is shown by a solid blue line boundary. Multi-ion batteries based on $\mathrm{AlCl}_{3}$ in 1-ethyl-3-methylimidazoliumchloride ([EMIm]Cl) as the electrolyte (referred to as $\mathrm{ABs}$, where $\mathrm{AlCl}_{4}, \mathrm{Al}_{2} \mathrm{Cl}_{7}$, and $\mathrm{Cl}^{-}$make up the active anions of insertion at the

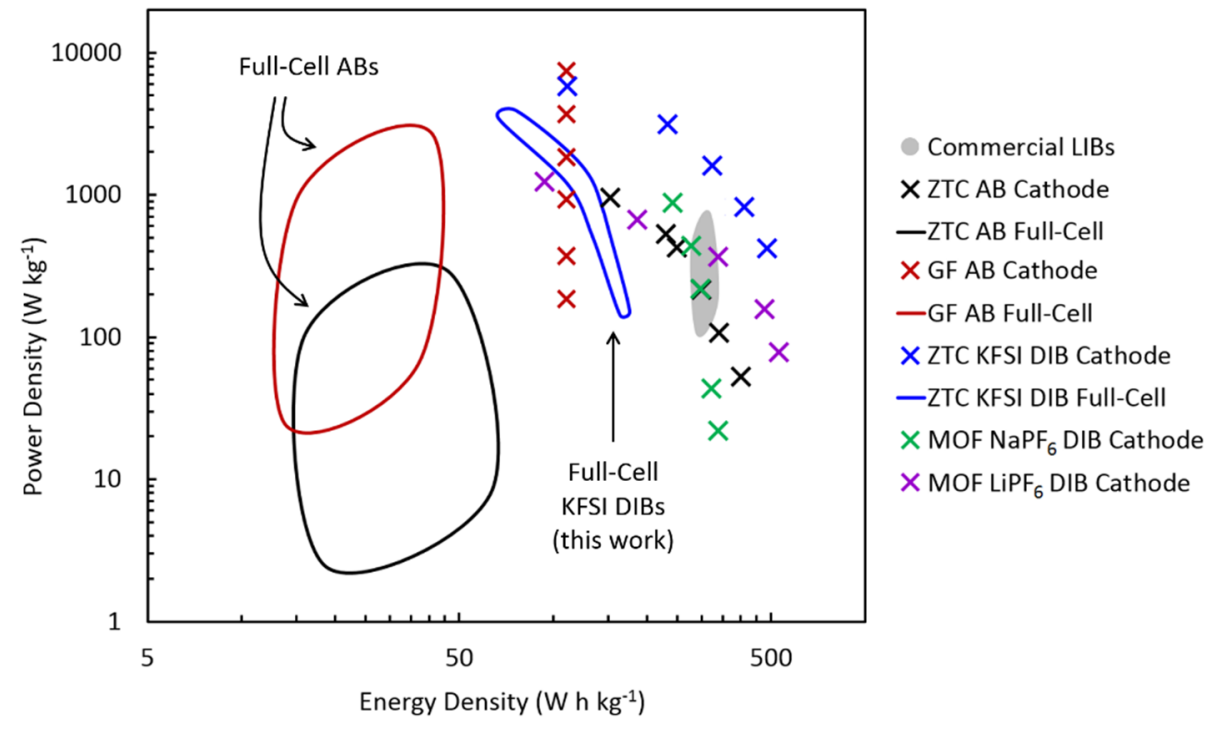

Figure 5. Gravimetric Ragone Plot comparing ZTC, 55 two $\mathrm{MOFs}^{33}, 34$, and graphitic foam (GF) ${ }^{16}$ as porous cathode materials in several dual-ion battery (DIB) chemistries: AlCl 3 -based aluminum batteries (ABs), LiPF6- and NaPF6-based DIBs, and KFSI DIBs as reported herein. Cathode-specific quantities (symbols) are shown in comparison to estimated full-cell quantities (solid lines) that depend on the precise charge storage mechanism and other factors such as the mass of additional components (cell case, current collectors, and separator). Typical values for commercial lithium-ion batteries (LIBs) are also shown (shaded gray region). 
cathode) comprising ZTC as the cathode are also shown. ${ }^{55}$ Comparatively, KFSI DIBs based on ZTC represent a significant improvement in both specific energy and power. This improvement is also extended to volumetric energy and power densities, whose values depend significantly on the maximum packing density of the porous ZTC cathode. This stark improvement over $\mathrm{AlCl}_{3}$-based $\mathrm{ABs}$ is primarily a consequence of the high electrolyte concentrations accessible to KFSI in EC/DMC solvent (up to $4.8 \mathrm{M}$ in this work) and the much higher operational voltage (3.0-3.5 V vs. $\mathrm{K} / \mathrm{K}^{+}$in KFSI DIBs as compared to $1.05 \mathrm{~V}$ vs. $\mathrm{Al} / \mathrm{Al}^{3+}$ in $\mathrm{ABs}$ ). Furthermore, the range of estimated full-cell energy and power densities in $A B s$ is much larger since the precise mechanism of charge storage remains unknown, and enacts a significant difference to the amount of electrolyte required for operation.

By contrast, the average operational voltage of ZTC-based KFSI DIBs is slightly lower than that of analogous cells based on graphite as the cathode $(4.7 \mathrm{~V}) ;{ }^{64}$ this is consistent with the pattern already reported for ABs based on ZTC and graphite. 14,18,55 Therefore, despite exhibiting a higher charge capacity, ZTC-based DIBs and ABs garner lower overall energy densities (a factor that is indeed assisted by the subsequent requirement for less total electrolyte owing to a lower quantity of exchanged ions during cycling). However, ZTC-based DIBs and $\mathrm{ABs}$ compensate for this lower energy density by exhibiting significantly higher rate capability and, therefore, power density, similarly to recently emerging devices commonly referred to as hybrid capacitors. ${ }^{69}$ Overall, KFSI DIBs based on a ZTC cathode have comparable energy density $\left(176 \mathrm{Wh} \mathrm{kg}^{-1}\right.$, $79.8 \mathrm{Wh} \mathrm{L}^{-1}$ ) to analogous graphite cells and much higher power density ( $3945 \mathrm{~W} \mathrm{~kg}^{-1}$ and $1095 \mathrm{~W} \mathrm{~L}^{-1}$ ). A comparison of gravimetric energy and power densities of ZTC-based KFSI DIBs to similar batteries comprising other porous materials such as MOFs and macroporous graphitic foam is shown in Figure 5.

A hurdle facing all DIBs and ABs employing microporous, high surface area materials as the cathode is the sloping voltage profile with no apparent plateaux, culminating in a varying discharge potential of the prepared cell. Such a chargestorage mechanism is typical of capacitive electrode materials, even including highly ordered MOFs that contain crystallographically distinct redox-active sites within their pores (e.g., at the open iron coordination centers in $\mathrm{Fe}_{2}$ (dobpdc)). This seems to imply that improving the regularity of the ZTC framework will not likely lead to a dramatic change in the shape of the voltage profile for large anion storage; rather, a sensible choice of insertion anion could instead lead to a higher and flatter voltage profile. In several recent methodological studies, for example, it has been reported that larger anions lead to higher average insertion/intercalation voltages in both porous DIB cathodes ${ }^{33}$ and graphite, ${ }^{70}$ although sizerelated effects in anion intercalation in graphite are also known to be complexly related to other electrolyte effects, such as ion-pair formation and self-aggregation. ${ }^{41}$ Future work remains to methodologically assess anion-size effects in ZTC-based DIBs and further establish electrolyte/solvent mixtures that will lead to higher energy and power densities yet.

\section{CONCLUSIONS}

Zeolite-templated carbon, an exclusively microporous, ordered carbon-based framework material, was demonstrated to reversibly oxidize and reduce between $2.65-4.7 \mathrm{~V}$ vs. $\mathrm{K} / \mathrm{K}^{+}$ and concomitantly undergo insertion and de-insertion of FSIanions, respectively. This reaction permits ZTC to be employed as the cathode material in high energy density KFSI dual-ion battery (DIB) cells, which are found to be comparable to state-of-the-art lithium-ion batteries despite being comprised of only highly abundant elements $(\mathrm{C}, \mathrm{K}, \mathrm{N}, \mathrm{S}, \mathrm{O}$, and F). Full-cells based on a ZTC cathode and electroplating/stripping of potassium metal at the anode demonstrate high volumetric and gravimetric capacities (up to $176 \mathrm{Wh} \mathrm{kg}^{-1}$ and 79.8 Wh $\mathrm{L}^{-1}$, respectively) after hundreds of cycles. The corresponding full-cell power densities (up to $3945 \mathrm{~W} \mathrm{~kg}^{-1}$ and $1095 \mathrm{~W} \mathrm{~L}^{-1}$ ) remain much higher than those of equivalent cells based on graphite, where anion insertion/de-insertion is significantly slower than within the $\sim 1.2 \mathrm{~nm}$ micropores of ZTC. Furthermore, both the energy and power densities of KFSI DIBs are significantly improved over analogous aluminum batteries owing to a much higher stable average voltage of operation (3.0-3.5 V vs. $\mathrm{K} / \mathrm{K}^{+}$) and high-concentration of electrolyte employed. The insertion of both solvent and FSI anions within the pores of ZTC was evidenced by solid-state NMR spectroscopy studies. In future work, zeolite-templated carbon is also likely to be an excellent model material for elucidating the mechanism of conductance of ions (and the extent to which they remain solvated or unsolvated) in nanometerscale pore spaces, a topic that remains poorly understood but which is crucial for the optimization of myriad electrochemical energy storage devices, ranging from supercapacitors to dual-ion batteries.

\section{EXPERIMENTAL SECTION}

Materials Synthesis. Pristine ZTC was prepared according to the established two-step method ${ }^{62,71}$ via liquid impregnation of zeolite $\mathrm{NaY}$ with furfuryl alcohol at room temperature and then chemical vapor deposition of propylene at $700{ }^{\circ} \mathrm{C}$; the zeolite template was removed upon repeated dissolution in aqueous HF. For comparison, two mesoporous templated carbons with larger characteristic pore sizes (MTC21 and MTC31) were also prepared by similar methods from MSU-H, an ordered mesoporous silica template. The synthesis methods are described in detail in the Supporting Information.

Materials Characterization. Powder X-ray diffraction (XRD) measurements were performed on a Rigaku Ultima IV diffractometer using $\mathrm{Cu} K \alpha_{1}$ radiation $(\lambda=1.54 \AA$ ) in reflection geometry. Nitrogen adsorption/desorption isotherms were measured at $77 \mathrm{~K}$ between $10^{-4}-100 \mathrm{kPa}$ using an automated volumetric instrument (3Flex, Micromeritics Instrument Corp.). Specific surface areas were calculated by the Brunauer-Emmett-Teller (BET) method between $\mathrm{P} / \mathrm{P}_{0}=$ 0.008-0.12 and micropore volumes were calculated by the Dubinin-Radushkevich (DR) method. ${ }^{72}$ Pore-size distributions were determined by non-localized density functional theory (NLDFT) calculations using a dedicated software package (MicroActive Share, Micromeritics Instrument Corp.), with a carbon slit-pore model. Transmission electron microscopy (TEM) was performed using a Jeol2200FS microscope operated at $200 \mathrm{kV}$ equipped with an in-column Omega-type filter. In order to improve the image contrast, the TEM images 
were acquired by selecting solely the zero-loss peak (zeroloss filtering) with a $15 \mathrm{eV}$ energy slit. Samples were prepared for TEM by sonicating the pristine carbon material in ethanol for $3 \mathrm{~min}$, placing a drop of the suspension on a holey carboncoated copper grid, and subsequently activating the material at $200{ }^{\circ} \mathrm{C}$ under vacuum $\left(10^{-4} \mathrm{mbar}\right)$. Elemental analysis was performed by the Molecular and Biomolecular Analysis Service (MoBiAS) at ETH Zürich. The elemental composition was determined by a combination of combustion analysis in $\mathrm{O}_{2}$ using a CHNS instrument (TruSpec Micro, LECO Corp., with IR and thermal conductivity detectors) and a chromatograph equipped with a thermal conductivity detector to determine the sulfur content (HEKAtech, Eurovector SRL). Fluorine content was determined by digestion of the sample as per the Schöniger method and quantification by ion chromatography.

NMR Spectroscopy. ${ }^{19} \mathrm{~F}$ and ${ }^{13} \mathrm{C}$ solid-state nuclear magnetic resonance (NMR) spectroscopy was performed using a Bruker 9.4 T spectrometer equipped with an Avance III console and a double resonance $2.5 \mathrm{~mm}$ solid-state probe head (with which the proton channel could be tuned to ${ }^{19} \mathrm{~F}$ frequencies). Samples were prepared for NMR as described in the Supporting Information, and filled into a $2.5 \mathrm{~mm}$ zirconia rotor in an argon glovebox. All experiments were performed at room temperature, either in static mode or while spinning the sample at $10 \mathrm{kHz}$ magic angle spinning (MAS) frequency. The ${ }^{19} \mathrm{~F}$ chemical shifts were referenced to $\mathrm{CFCl}_{3}$ and the ${ }^{13} \mathrm{C}$ chemical shifts were referenced to $\mathrm{Si}\left(\mathrm{CH}_{3}\right)_{4}$. The number of transients acquired was 1024 for ${ }^{19} \mathrm{~F}$ NMR experiments and 2048 for ${ }^{13} \mathrm{C}$ NMR experiments. All spectra were acquired without decoupling using one-pulse excitation sequences with pulse lengths of $5.75 \mu$ s for ${ }^{19} \mathrm{~F}$ (corresponding to a $90^{\circ}$ pulse) and $1.1 \mu$ s for ${ }^{13} \mathrm{C}$ (corresponding to a $30^{\circ}$ pulse). The recycle delay was set to $5 \mathrm{~s}$.

${ }^{19} \mathrm{~F}$ solution-state NMR spectroscopy was performed using a Bruker 11.7 T spectrometer equipped with a PABBO probe head and an Avance III console. Samples were filled into conventional $5 \mathrm{~mm}$ glass NMR tubes. Sealed glass capillaries containing $\mathrm{C}_{6} \mathrm{D}_{6}$ were added to the sample for locking to the deuterium signal of the deuterated benzene. The number of transients acquired was 256 . Inverse gated $\mathrm{H}-1$ pulse sequences were used with pulse lengths of $15.0 \mu$ s for ${ }^{19} \mathrm{~F}$. During the acquisition of ${ }^{19} \mathrm{~F}$ NMR spectra, a WALTZ16 decoupling sequence was performed using $80 \mu$ s proton decoupling pulses.

Electrochemical Cell Materials. The following materials were used in the preparation of electrochemical cells: potassium bis(fluorosulfonyl)imide (KFSI, >99.9\%, Suzhou Fluolyte Co.), ethylene carbonate (EC, battery grade, BASF), dimethyl carbonate (DMC, battery grade, BASF), potassium (99.5\%, cubes in oil, Sigma-Aldrich), and glass microfiber discs $(0.67 \mathrm{~mm} \times 257 \mathrm{~mm}, \mathrm{GF} / \mathrm{D}$ grade, catalogue number 1823-257, Whatman).

Electrolyte Preparation. The electrolyte was prepared by slowly mixing KFSI powder and EC/DMC solvent (in a 1:1 ratio, by weight) under inert $\mathrm{Ar}$ atmosphere $\left(<0.1 \mathrm{ppm} \mathrm{H}_{2} \mathrm{O} / \mathrm{O}_{2}\right)$ in the concentration specified (typically $4.8 \mathrm{M}$ ). A highly exothermic reaction takes place upon mixing, resulting in the eventual formation of a viscous, transparent liquid.

Current Collector Coating. To improve cycling stability under high-voltage conditions, the stainless steel coin-type cell caps (316L, Hohsen Corp.) were coated with TiN by pulsed DC magnetron sputtering using a titanium target under a flowing
$\mathrm{Ar} / \mathrm{N}_{2}$ atmosphere (held at a molar ratio of 3.6:1 at a total flow rate of $105.5 \mathrm{sccm}$ ) at a pressure of $0.5 \mathrm{~Pa}$, similar to a previously described method. ${ }^{73,74}$ The substrate and target were both pre-sputtered for $5 \mathrm{~min}$ in pure Ar before deposition. The target was then intentionally poisoned under a flowing $\mathrm{Ar} / \mathrm{N}_{2}$ atmosphere (held at a molar ratio of 2.75:1 at a total flow rate of $112.5 \mathrm{sccm}$ ) for $5 \mathrm{~min}$. During deposition, the target power and temperature were set to $0.58 \mathrm{~W} \mathrm{~cm}^{-2}$ and $200{ }^{\circ} \mathrm{C}$, respectively. The sides of the current collectors, parallel to the sputtering beam and thus less covered with TiN were further protected with a thin layer of Araldite Rapid two-component glue.

Electrochemical Cell Preparation. Stainless steel cointype cells (316L, Hohsen Corp.) were assembled in a glovebox under inert $\mathrm{Ar}$ atmosphere $\left(<0.1 \mathrm{ppm} \mathrm{H}_{2} \mathrm{O} / \mathrm{O}_{2}\right)$. A thin potassium film pressed onto stainless steel was used as both the reference and counter electrodes. The working electrode was prepared without the use of any binder, conductive additive, or solvent, and the electrolyte was used as prepared above. To assemble the cell, the cathode material (in dry powder form) was homogeneously dispersed onto the TiN-coated stainlesssteel cell cap. A single glass microfiber disc was then placed on top as the separator, and saturated with $\sim 300 \mu \mathrm{L}$ electrolyte, added by wetting the exposed separator at the edge of the cell. Lastly, a disc of stainless-steel containing a thin layer of potassium was then placed on top and the cell was shut, pressing all the components into contact. Each cell contained loadings of 0.6-4.1 mg of active cathode material.

Electrochemical Measurements. The prepared cells were electrochemically cycled after a waiting time of $2 \mathrm{~h}$ (under open circuit conditions to allow complete wetting of the carbon cathode), typically between $2.65-4.7 \mathrm{~V}$ vs. $\mathrm{K} / \mathrm{K}^{+}$, on a multi-channel workstation (CT2001A, 0.005-1 mA, Lanhe Corp.). Cyclic voltammetry was performed using a separate multi-channel workstation (MPG-2, Bio-Logic SAS).

To determine the gravimetric quantities of specific energy and power of the cathode alone, the measured mass of the dry carbon material (prior to first charge) was used: typically 0.6$4.1 \mathrm{mg}$. To determine the corresponding volumetric quantities, the bulk density of each cathode material was measured in the dried state: e.g., $0.2 \mathrm{~g} \mathrm{~mL}^{-1}$ for ZTC. Conversions of cathode-specific to full-cell quantities were then made by several methods to account for the additional mass and volume of the electrolyte and other components (see the Supporting Information for details regarding all calculations).

\section{ASSOCIATED CONTENT}

Supporting Information. Synthesis details, SEM and TEM imaging, $\mathrm{N}_{2}$ adsorption analysis, cyclic voltammetry, additional galvanostatic cycling, ${ }^{19} \mathrm{~F}$ static NMR and ${ }^{13} \mathrm{C}$ MAS NMR spectra, elemental analysis, and full-cell energy/power density calculations. This material is available free of charge via the Internet at http://pubs.acs.org.

\section{AUTHOR INFORMATION}

\section{Corresponding Authors}

*nstadie@montana.edu, mvkovalenko@ethz.ch

\section{Author Contributions}

The manuscript was written through contributions of all authors. 
Notes

The authors declare no competing financial interest.

\section{ACKNOWLEDGMENTS}

We thank Devin McGlamery for assistance with SEM measurements, Hans Swenson for assistance with $\mathrm{N}_{2}$ adsorption measurements, and Shutao Wang for assistance in the preparation of ZTC electrodes. The authors are grateful to the Micro Elemental Analysis Service of the Laboratory for Organic Chemistry at ETH Zürich, the Empa Electron Microscopy Center and Laboratory for Mechanics of Materials \& Nanostructures, and the Montana Nanotechnology Facility (MONT, supported by the National Science Foundation grant ECCS-1542210) for access to their instruments and technical assistance. This research is part of the activities of SCCER HaE (Heat and Electricity Storage), which is financially supported by Innosuisse - Swiss Innovation Agency. L.P. acknowledges financial support from the Scholarship Fund of the Swiss Chemical Industry (SSCI Award 2015). N.P.S. acknowledges financial support from start-up funding provided by Montana State University.

\section{REFERENCES}

(1) Wang, M.; Tang, Y., A Review on the Features and Progress of Dual-Ion Batteries. Adv. Energy Mater. 2018, 8, 1703320.

(2) Rodríguez-Pérez, I. A.; Ji, X., Anion Hosting Cathodes in DualIon Batteries. ACS Energy Lett. 2017, 2 (8), 1762-1770.

(3) Schoetz, T.; de Leon, C. P.; Ueda, M.; Bund, A., PerspectiveState of the Art of Rechargeable Aluminum Batteries in Non-Aqueous Systems. J. Electrochem. Soc. 2017, 164 (14), A3499-A3502.

(4) Zhang, Y.; Liu, S.; Ji, Y.; Ma, J.; Yu, H., Emerging Nonaqueous Aluminum-Ion Batteries: Challenges, Status, and Perspectives. Adv. Mater. 2018, 1706310.

(5) Zhao, H.; Xu, J.; Yin, D.; Du, Y., A Minireview of Electrolytes for Batteries with Earth-Abundant Metallic Anodes. Chem. Eur. J. 2018 (6) Jobert, A.; Touzain, P.; Bonnetain, L., Insertion des Ions PF6-, AsF6- et SbF6- dans le Graphite par Methode Electrochimique. Caracterisation des Produits Obtenus. Carbon 1981, 19 (3), 193-198.

(7) Placke, T.; Bieker, P.; Lux, S. F.; Fromm, O.; Meyer, H.-W.; Passerini, S.; Winter, M., Dual-Ion Cells Based on Anion Intercalation into Graphite from Ionic Liquid-Based Electrolytes. Z. Phys. Chem. 2012, 226 (5-6), 391-407.

(8) Placke, T.; Fromm, O.; Lux, S. F.; Bieker, P.; Rothermel, S.; Meyer, H.-W.; Passerini, S.; Winter, M., Reversible Intercalation of Bis(trifluoromethanesulfonyl)imide Anions from an Ionic Liquid Electrolyte into Graphite for High Performance Dual-Ion Cells. J. Electrochem. Soc. 2012, 159 (11), A1755-A1765.

(9) Beltrop, K.; Beuker, S.; Heckmann, A.; Winter, M.; Placke, T., Alternative Electrochemical Energy Storage: Potassium-Based DualGraphite Batteries. Energy Environ. Sci. 2017, 10 (10), 2090-2094.

(10) Fan, L.; Liu, Q.; Chen, S.; Xu, Z.; Lu, B., Soft Carbon as Anode for High-Performance Sodium-Based Dual Ion Full Battery. Adv. Energy Mater. 2017, 7 (14), 1602778.

(11) Ji, B.; Zhang, F.; Wu, N.; Tang, Y., A Dual-Carbon Battery Based on Potassium-Ion Electrolyte. Adv. Energy Mater. 2017, 7 (20), 1700920 .

(12) Ji, B.; Zhang, F.; Song, X.; Tang, Y., A Novel Potassium-IonBased Dual-Ion Battery. Adv. Mater. 2017, 29 (19), 1700519.

(13) Fan, L.; Liu, Q.; Chen, S.; Lin, K.; Xu, Z.; Lu, B., PotassiumBased Dual Ion Battery with Dual-Graphite Electrode. Small 2017, 13 (30), 1701011.

(14) Kravchyk, K. V.; Wang, S.; Piveteau, L.; Kovalenko, M. V., Efficient Aluminum Chloride-Natural Graphite Battery. Chem. Mater. 2017, 29 (10), 4484-4492.

(15) Wang, S.; Kravchyk, K. V.; Krumeich, F.; Kovalenko, M. V., Kish Graphite Flakes as a Cathode Material for an Aluminum ChlorideGraphite Battery. ACS Appl. Mater. Interfaces 2017, 9 (34), 2847828485.

(16) Lin, M.-C.; Gong, M.; Lu, B.; Wu, Y.; Wang, D.-Y.; Guan, M.; Angell, M.; Chen, C.; Yang, J.; Hwang, B.-J.; Dai, H., An Ultrafast Rechargeable Aluminium-Ion Battery. Nature 2015, 520, 324-328.
(17) Liu, Z.; Wang, J.; Ding, H.; Chen, S.; Yu, X.; Lu, B., Carbon Nanoscrolls for Aluminum Battery. ACS Nano 2018, 12 (8), 8456-8466. (18) Yu, X.; Wang, B.; Gong, D.; Xu, Z.; Lu, B., Graphene Nanoribbons on Highly Porous 3D Graphene for High-Capacity and Ultrastable Al-Ion Batteries. Adv. Mater. 2017, 29 (4), 1604118.

(19) Yang, H.; Shi, X.; Deng, T.; Qin, T.; Sui, L.; Feng, M.; Chen, H.; Zhang, W.; Zheng, W., Carbon-Based Dual-Ion Battery with Enhanced Capacity and Cycling Stability. ChemElectroChem 2018, 5 (23), 36123618.

(20) Zhang, Q.; Wang, L.; Wang, J.; Xing, C.; Ge, J.; Fan, L.; Liu, Z.; Lu, X.; Wu, M.; Yu, X., Low-Temperature Synthesis of Edge-Rich Graphene Paper for High-Performance Aluminum Batteries. Energy Storage Mater. 2018, 15 361-367.

(21) Chen, S.; Wang, J.; Fan, L.; Ma, R.; Zhang, E.; Liu, Q.; Lu, B., An Ultrafast Rechargeable Hybrid Sodium-Based Dual-Ion Capacitor Based on Hard Carbon Cathodes. Adv. Energy Mater. 2018, 1800140.

(22) Zhang, F.; Ji, B.; Tong, X.; Sheng, M.; Zhang, X.; Lee, C. S.; Tang, Y., A Dual-Ion Battery Constructed with Aluminum Foil Anode and Mesocarbon Microbead Cathode via an Alloying/Intercalation Process in an Ionic Liquid Electrolyte. Adv. Mater. Interfaces 2016, 3 (23).

(23) Liao, H.-J.; Chen, Y.-M.; Kao, Y.-T.; An, J.-Y.; Lai, Y.-H.; Wang, D.-Y., Freestanding Cathode Electrode Design for High-Performance Sodium Dual-Ion Battery. J. Phys. Chem. C 2017, 121 (44), 2446324469.

(24) Rodríguez-Pérez, I. A.; Jian, Z.; Waldenmaier, P. K.; Palmisano, J. W.; Chandrabose, R. S.; Wang, X.; Lerner, M. M.; Carter, R. G.; Ji, X., A Hydrocarbon Cathode for Dual-Ion Batteries. ACS Energy Lett. 2016, 1 (4), 719-723.

(25) Rodríguez-Pérez, I. A.; Bommier, C.; Fuller, D. D.; Leonard, D. P.; Williams, A. G.; Ji, X., Toward Higher Capacities of Hydrocarbon Cathodes in Dual-Ion Batteries. ACS Appl. Mater. Interfaces 2018, 10 (50), 43311-43315.

(26) Deunf, E.; Moreau, P.; Quarez, E.; Guyomard, D.; Dolhem, F.; Poizot, P., Reversible Anion Intercalation in a Layered Aromatic Amine: a High-Voltage Host Structure for Organic Batteries. J. Mater. Chem. A 2016, 4 (16), 6131-6139.

(27) Fan, L.; Liu, Q.; Xu, Z.; Lu, B., An Organic Cathode for Potassium Dual-Ion Full Battery. ACS Energy Lett. 2017, 2 (7), 16141620.

(28) Walter, M.; Kravchyk, K. V.; Böfer, C.; Widmer, R.; Kovalenko, M. V., Polypyrenes as High-Performance Cathode Materials for Aluminum Batteries. Adv. Mater. 2018, 30 (15), 1705644.

(29) Hudak, N. S., Chloroaluminate-Doped Conducting Polymers as Positive Electrodes in Rechargeable Aluminum Batteries. J. Phys. Chem. C 2014, 118 (10), 5203-5215.

(30) Reddy, M. A.; Fichtner, M., Batteries Based on Fluoride Shuttle. J. Mater. Chem. 2011, 21 (43), 17059-17062.

(31) Zhou, Z.; Li, N.; Yang, Y.; Chen, H.; Jiao, S.; Song, W. L.; Fang, D., Ultra-Lightweight 3D Carbon Current Collectors: Constructing AllCarbon Electrodes for Stable and High Energy Density Dual-Ion Batteries. Adv. Energy Mater. 2018, 8 (26), 1801439.

(32) Microporous materials are designated by the IUPAC as having a characteristic pore width of $<2 \mathrm{~nm}$, and hence representing the narrowest extreme in nanoscale porosity.

(33) Aubrey, M. L.; Long, J. R., A Dual-Ion Battery Cathode via Oxidative Insertion of Anions in a Metal-Organic Framework. J. Am. Chem. Soc. 2015, 137 (42), 13594-13602.

(34) Zhang, Z.; Yoshikawa, H.; Awaga, K., Discovery of a "Bipolar Charging" Mechanism in the Solid-State Electrochemical Process of a Flexible Metal-Organic Framework. Chem. Mater. 2016, 28 (5), 12981303.

(35) Dühnen, S.; Nölle, R.; Wrogemann, J.; Winter, M.; Placke, T., Reversible Anion Storage in a Metal-Organic Framework for Dual-Ion Battery Systems. J. Electrochem. Soc. 2019, 166 (3), A5474-A5482.

(36) Nishihara, H.; Kyotani, T., Templated Nanocarbons for Energy Storage. Adv. Mater. 2012, 24 (33), 4473-4498.

(37) Meyers, C. J.; Shah, S. D.; Patel, S. C.; Sneeringer, R. M.; Bessel, C. A.; Dollahon, N. R.; Leising, R. A.; Takeuchi, E. S., Templated Synthesis of Carbon Materials from Zeolites (Y, Beta, and ZSM-5) and a Montmorillonite Clay (K10): Physical and Electrochemical Characterization. J. Phys. Chem. B 2001, 105, 2143-2152.

(38) Lv, Y.; Wu, Z.; Qian, X.; Fang, Y.; Feng, D.; Xia, Y.; Tu, B.; Zhao, D., Site-Specific Carbon Deposition for Hierarchically Ordered 
Core/Shell-Structured Graphitic Carbon with Remarkable Electrochemical Performance. ChemSusChem 2013, 6 (10), 1938-1944. (39) Nishihara, H.; Kyotani, T., Zeolite-Templated Carbons Three-dimensional Microporous Graphene Frameworks. Chem. Commun. 2018, 54, 5648-5673.

(40) Huggins, R. A., Mixed-Conducting Host Structures into which either Cations or Anions can be Inserted. Solid state ionics 1998, 113 533-544.

(41) Beltrop, K.; Meister, P.; Klein, S.; Heckmann, A.; Gruenebaum, M.; Wiemhöfer, H.-D.; Winter, M.; Placke, T., Does Size Really Matter? New Insights into the Intercalation Behavior of Anions into a GraphiteBased Positive Electrode for Dual-Ion Batteries. Electrochim. Acto 2016, 209, 44-55.

(42) Sun, L.; Campbell, M. G.; Dincă, M., Electrically Conductive Porous Metal-Organic Frameworks. Angew. Chem. Int. Ed. 2016, 55 (11), 3566-3579.

(43) Salitra, G.; Soffer, A.; Eliad, L.; Cohen, Y.; Aurbach, D., Carbon Electrodes for Double-Layer Capacitors I. Relations Between Ion and Pore Dimensions. J. Electrochem. Soc. 2000, 147 (7), 2486-2493.

(44) Zhang, L. L.; Gu, Y.; Zhao, X., Advanced Porous Carbon Electrodes for Electrochemical Capacitors. J. Mater. Chem. A 2013, 1 (33), 9395-9408.

(45) Nishihara, H.; Fujimoto, H.; Itoi, H.; Nomura, K.; Tanaka, H.; Miyahara, M. T.; Bonnaud, P. A.; Miura, R.; Suzuki, A.; Miyamoto, N., Graphene-Based Ordered Framework with a Diverse Range of Carbon Polygons Formed in Zeolite Nanochannels. Carbon 2018, 129, 854-862. (46) Lee, H.; Kim, K.; Kang, S.-H.; Kwon, Y.; Kim, J. H.; Kwon, Y.-K.; Ryoo, R.; Park, J. Y., Extremely High Electrical Conductance of Microporous 3D Graphene-Like Zeolite-Templated Carbon Framework. Sci. Rep. 2017, 7, 11460.

(47) Ania, C. O.; Khomenko, V.; Raymundo-Piñero, E.; Parra, J. B.; Béguin, F., The Large Electrochemical Capacitance of Microporous Doped Carbon Obtained by Using a Zeolite Template. Adv. Funct. Mater. 2007, 17 (11), 1828-1836.

(48) Kajdos, A.; Kvit, A.; Jones, F.; Jagiello, J.; Yushin, G., Tailoring the Pore Alignment for Rapid Ion Transport in Microporous Carbons. J. Am. Chem. Soc. 2010, 132 (10), 3252-3253.

(49) Portet, C.; Yang, Z.; Korenblit, Y.; Gogotsi, Y.; Mokaya, R.; Yushin, G., Electrical Double-layer Capacitance of Zeolite-Templated Carbon in Organic Electrolyte. J. Electrochem. Soc. 2009, 156, 1-6.

(50) Itoi, H.; Nishihara, H.; Kogure, T.; Kyotani, T., ThreeDimensionally Arrayed and Mutually Connected 1.2-nm Nanopores for High-Performance Electric Double Layer Capacitor. J. Am. Chem. Soc. 2011, 133, 1165-1167.

(51) Nishihara, H.; Itoi, H.; Kogure, T.; Hou, P.-X.; Touhara, H.; Okino, F.; Kyotani, T., Investigation of the Ion Storage/Transfer Behavior in an Electrical Double-layer Capacitor by Using Ordered Microporous Carbons as Model Materials. Chem. Eur. J. 2009, 15, 53555363.

(52) Nueangnoraj, K.; Ruiz-Rosas, R.; Nishihara, H.; Shiraishi, S.; Morallon, E.; Cazorla-Amoros, D.; Kyotani, T., Carbon-Carbon Asymmetric Aqueous Capacitor by Pseudocapacitive Positive and Stable Negative Electrodes. Carbon 2014, 67, 792-794.

(53) Korenblit, Y.; Kajdos, A.; West, W. C.; Smart, M. C.; Brandon, E. J.; Kvit, A.; Jagiello, J.; Yushin, G., In Situ Studies of Ion Transport in Microporous Supercapacitor Electrodes at Ultralow Temperatures. Adv. Funct. Mater. 2012, 22 (8), 1655-1662.

(54) Moon, J. S.; Kim, H.; Lee, D. C.; Lee, J. T.; Yushin, G., Increasing Capacitance of Zeolite-Templated Carbons in Electric Double Layer Capacitors. J. Electrochem. Soc. 2015, 162 (5), A5070-A5076.

(55) Stadie, N. P.; Wang, S.; Kravchyk, K. V.; Kovalenko, M. V., Zeolite-Templated Carbon as an Ordered Microporous Electrode for Aluminum Batteries. ACS Nano 2017, 11 (2), 1911-1919.

(56) Kim, K.; Lee, T.; Kwon, Y.; Seo, Y.; Song, J.; Park, J. K.; Lee, H.; Park, J. Y.; Ihee, H.; Cho, S. J.; Ryoo, R., Lanthanum-Catalysed Synthesis of Microporous 3D Graphene-Like Carbons in a Zeolite Template. Nature 2016, 535, 131-135.

(57) Beltrop, K.; Qi, X.; Hering, T.; Röser, S.; Winter, M.; Placke, T., Enabling Bis(fluorosulfonyl)imide-Based Ionic Liquid Electrolytes for Application in Dual-Ion Batteries. J. Power Sources 2018, 373, 193-202. (58) Karu, K.; Ruzanov, A.; Ers, H.; Ivaništšev, V.; Lage-Estebanez, I.; García de la Vega, J. M., Predictions of Physicochemical Properties of Ionic Liquids with DFT. Computation 2016, 4 (3), 25.

(59) Sun, H.; Wang, W.; Yu, Z.; Yuan, Y.; Wang, S.; Jiao, S., A New Aluminium-Ion Battery with High Voltage, High Safety and Low Cost. Chem. Commun. 2015, 51, 11892-11895.

(60) Wu, Y.; Gong, M.; Lin, M.-C.; Yuan, C.; Angell, M.; Huang, L.; Wang, D.-Y.; Zhang, X.; Yang, J.; Hwang, B.-J.; Dai, H., 3D Graphitic Foams Derived from Chloroaluminate Anion Intercalation for Ultrafast Aluminum-Ion Battery. Adv. Mater. 2016, 28, 9218-9222.

(61) Jiao, S.; Lei, H.; Tu, J.; Zhu, J.; Wang, J.; Mao, X., An Industrialized Prototype of the Rechargeable $\mathrm{Al} / \mathrm{AlCl} 3-$ [EMIm] Cl/Graphite Battery and Recycling of the Graphitic Cathode into Graphene. Carbon 2016, 109, 276-281.

(62) Ma, Z.; Kyotani, T.; Tomita, A., Synthesis Methods for Preparing Microporous Carbons with a Structural Regularity of Zeolite Y. Carbon 2002, 40 (13), 2367-2374.

(63) Rouquerol, J.; Llewellyn, P.; Rouquerol, F., Is the BET Equation Applicable to Microporous Adsorbents? Stud. Surf. Sci. Catal. 2007, 160, 49-56.

(64) Kravchyk, K. V.; Bhauriyal, P.; Piveteau, L.; Guntlin, C. P.; Pathak, B.; Kovalenko, M. V., High-Energy-Density Dual-Ion Battery for Stationary Storage of Electricity Using Concentrated Potassium Fluorosulfonylimide. Nat. Commun. 2018, 9, 4469.

(65) Gogotsi, Y.; Penner, R. M., Energy Storage in NanomaterialsCapacitive, Pseudocapacitive, or Battery-like? ACS Nano 2018, 12, 2081-2083.

(66) Nueangnoraj, K.; Nishihara, H.; Ishii, T.; Yamamoto, N.; Itoi, H.; Berenguer, R.; Ruiz-Rosas, R.; Cazorla-Amorós, D.; Morallón, E.; Ito, M.; Kyotani, T., Pseudocapacitance of Zeolite-Templated Carbon in Organic Electrolytes. Energy Storage Mater. 2015, 1, 35-41.

(67) Simoes, M. C.; Hughes, K. J.; Ingham, D. B.; Ma, L.; Pourkashanian, M., Estimation of the Thermochemical Radii and Ionic Volumes of Complex Ions. Inorg. Chem. 2017, 56 (13), 7566-7573.

(68) Beran, M.; Př́íhoda, J.; Žák, Z.; Černík, M., A New Route to the Syntheses of Alkali Metal Bis(fluorosulfuryl)imides: Crystal Structure of LiN(SO2F)2. Polyhedron 2006, 25 (6), 1292-1298.

(69) Dong, L.; Ma, X.; Li, Y.; Zhao, L.; Liu, W.; Cheng, J.; Xu, C.; Li, B.; Yang, Q.-H.; Kang, F., Extremely Safe, High-Rate and Ultralong-Life ZincIon Hybrid Supercapacitors. Energy Storage Mater. 2018, 13, 96-102.

(70) Katinonkul, W.; Lerner, M. M., Graphite Intercalation Compounds with Large Fluoroanions. J. Fluorine Chem. 2007, 128 (4), 332-335.

(71) Matsuoka, K.; Yamagishi, Y.; Yamazaki, T.; Setoyama, N.; Tomita, A.; Kyotani, T., Extremely high Microporosity and Sharp Pore Size Distribution of a Large Surface Area Carbon Prepared in the Nanochannels of Zeolite Y. Carbon 2005, 43, 855-894.

(72) Rouquerol, F.; Rouquerol, J.; Sing, K. S. W., Adsorption by Powders and Porous Solids: Principles, Methodology, and Applications. Academic Press: San Diego, 1999; p xvi, 467 p.

(73) Wang, S.; Kravchyk, K. V.; Filippin, A. N.; Widmer, R.; Tiwari, A.; Buecheler, S.; Bodnarchuk, M. I.; Kovalenko, M. V., Overcoming the High-Voltage Limitations of Li-Ion Batteries using a Titanium Nitride Current Collector. ACS Appl. Energy Mater. 2019, 2 (2), 974-978.

(74) Wang, S.; Kravchyk, K. V.; Filippin, A. N.; Müller, U.; Tiwari, A. N.; Buecheler, S.; Bodnarchuk, M. I.; Kovalenko, M. V., Aluminum Chloride-Graphite Batteries with Flexible Current Collectors Prepared from Earth-Abundant Elements. Adv. Sci. 2018, 5 (4), 1700712. 